\title{
O SERTÃO VIROU PARQUE: NATUREZA, CULTURA E PROCESSOS DE PATRIMONIALIZAÇÃO
}

The "sertão" became park: nature, culture and heritage processes

\section{ANNELISE CAETANO FRAGA FERNANDES}




\title{
RESUMO
}

Desde o século XIX os parques nacionais tornaram-se um importante instrumento de patrimonialização da natureza, produzindo uma visão utópica da relação homem-natureza e sentimentos de integração simbólica e territorial da sociedade nacional. Esse modelo, no entanto, passou a ser questionado por modos culturalmente diversos de apropriação material e simbólica da natureza. Confrontando as novas orientações socioambientais e de diversidade cultural nas políticas de patrimônio, o presente artigo descreve as formas de resistência e afirmação da paisagem do chamado Sertão Carioca frente ao mito moderno da natureza intocada, imposto pela criação do Parque Estadual da Pedra Branca, na cidade do Rio de Janeiro.

PalaVras-CHAVE: patrimônio, parques nacionais, uso público, conservacionismo, socioambientalismo.

\begin{abstract}
Since the XIXth century the national parks became an important instrument of natural heritage, producing an utopic vision of the man-nature relationship and feelings of symbolic and territorial integration of the national society. This model, however, began to be questioned by culturally diverse ways of material and symbolic uses of nature. Confronting the new socioenvironmental and cultural diversity guidelines in heritage policies, this article describes the forms of resistance and affirmation of the landscape of the so-called "Sertão Carioca" in the face of the modern myth of untouched nature imposed by the creation of the State Park of Pedra Branca, in the city of Rio de Janeiro.
\end{abstract}

KeYwORDs: heritage, national parks, public use, conservation, socioenvironmentalism.

\section{RÉSUMÉ}

Depuis le XIXème siècle, les parcs nationaux sont devenus un important instrument du patrimoine naturel, produisant une vision utopique de la relation homme-nature et des sentiments d'intégration symbolique et territoriale de la société nationale. Ce modèle, cependant, a été mis en question par des modes culturellement divers d'appropriation matérielle et symbolique de la nature. En confrontant les nouvelles orientations socio-environnementales et de diversité culturelle présentes dans les politiques du patrimoine, cet article décrit les formes de résistance et d'affirmation du paysage du "Sertão Carioca" en face du mythe moderne de la nature intacte imposé par la création du Parc de Pedra Branca, dans la ville de Rio de Janeiro.

Mots-CLÉs: patrimoine, parcs nationaux, utilisation publique, conservatisme, mouvent socio-environnemental. 


\section{INTRODUÇÃO}

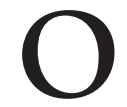

s parques nacionais são espaços destinados à conservação da natureza e admitem a presença humana apenas indiretamente, ou seja, para fins de visitação e pesquisa científica. Esta definição, que no Brasil assumiu status legal através do Sistema Nacional de Unidades de Conservação' (SNUC, Lei 9.985/2000), além de nos ajudar a eliminar outros sentidos possíveis de utilização do termo parque, tais como parque aquático, parque infantil, parque de diversões etc., demonstra, por outro lado, o que em parte os parques sempre foram, desde sua primeira aparição em Yellowstone, nos Estados Unidos, no ano de 1872: áreas naturais destinadas ao lazer tipicamente urbano.

Sua dimensão lúdica, no entanto, não aparece desvinculada da possibilidade de conservação da natureza, revelando em sua origem uma tensão, ou melhor dizendo, uma oscilação entre ideais contraditórios. No conjunto de representações sobre os parques, podem ser identificados tanto os ideais românticos de integração do homem com o ambiente a partir da contemplação da natureza, quanto os valores iluministas de interesse genuíno pelo mundo selvagem e os ideais de uso público desses espaços verdes, que poderiam sofrer intervenções paisagísticas para melhor receber seus visitantes.

Ao conceito de uso público, associado à apreciação de paisagens de grande beleza cênica, únicas na sua existência e, portanto, expressão autêntica do legado de um povo, aos parques, inicialmente chamados de parques públicos, foi acrescido o adjetivo nacionais, indicando que deveriam ser tutelados pelo Estado como um patrimônio da nação. Neste sentido, mesmo que um parque seja estadual ou municipal, administrado por outras instâncias federativas, permanecem os mesmos princípios e valores associados aos parques nacionais.

Tal como ocorreu com o patrimônio histórico e artístico, a narrativa da "perda" (Gonçalves, 1995: 235) - justificativa baseada na ameaça de desaparecimento desses bens (recursos naturais estratégicos, belezas cênicas típicas de um país) - incentivou a política de criação de parques e posteriormente de outras categorias de áreas com proteção integral.

A transformação de espaços naturais em bens públicos exige sua gestão pelo Estado. São impostos modelos padronizados de uso e acesso a esses recursos. Parte-se do princípio de que esse modelo de fruição da natureza é compartilhado por toda a sociedade nacional. 
Entretanto, a despeito deste (e em reação a este) modelo oficial de conservação consagrado pelos parques, formas locais e culturalmente diversas de apropriação da natureza e do território foram afirmadas no contexto da redemocratização do Brasil na década de 1980 e passaram a ser identificadas como manifestações autênticas e igualmente passíveis de patrimonialização (Santilli, 2005).

0 presente artigo tem como objetivo descrever as disputas entre esses dois modelos distintos de patrimonialização em áreas protegidas, discutindo um caso específico: o do Parque Estadual da Pedra Branca (PEPB). Criado em 1974 de acordo com o mesmo conjunto de valores que orientavam a criação dos parques nacionais, o PEPB fazia parte do chamado Sertão Carioca - a zona rural do município do Rio de Janeiro -, que abrigava uma população de perfil rural agrícola com forte relação de dependência dos recursos naturais locais para garantir seu sustento e reprodução social. Passadas quatro décadas de criação desse território protegido, as marcas do Sertão Carioca não se apagaram. Ao contrário, refletindo as novas conjunturas de participação da sociedade brasileira, a consolidação de valores socioambientais e os direitos multiculturais expressos na Constituição e em outras legislações infraconstitucionais, estão em curso processos de reconhecimento dos direitos culturais e territoriais de seus moradores e a patrimonialização de seus modos de vida, construindo-se formas polissêmicas de contar sua história.

Quando mencionamos aqui a patrimonialização, nos referimos aos valores e práticas que podem ancorar os processos de institucionalização. Deste modo, procuramos tratar neste artigo dos debates recentes na arena pública (mídia, fóruns de participação, instituições, redes sociais) $)^{2}$ sobre o que merece ser protegido no PEPB.

Por fim, é importante dizer que a descrição deste sertão que virou parque é significativa para se pensar de modo mais amplo inúmeros outros sertões transformados em parques. Em outras palavras, ela versa sobre as disputas entre modelos de patrimonialização que envolvem natureza e cultura. Colabora para esta perspectiva o fato de que parte significativa do Sertão Carioca - sua paisagem, belezas naturais e tipos humanos - foi retratada em obra homônima, no ano de 1933, pelo cronista Armando Magalhães Corrêa. ${ }^{3}$ A obra já seria por si só um importante registro etnográfico dos modos de vida locais, desconstruindo concepções consagradas pelo imaginário conservacionista a respeito de uma suposta natureza intocada a ser preservada. Contudo, mais do que isso, O Sertão Carioca, de acordo com Sarmento (1998), pode ser compreendido como parte de uma matriz discursiva da sertanidade inaugurada pela obra de Euclides da Cunha, Os Sertões, e que procura pensar a identidade nacional a partir da ambiguidade entre uma cultura autêntica, rústica, em contraste com as iniciativas de modernização da sociedade brasileira. 
Nos termos de Sarmento (1998), portanto, O Sertão Carioca produz um sertão formal, na medida em que falar sobre as "veredas da capital" significa também falar sobre muitos outros sertões e, portanto, sobre os dilemas de nosso processo civilizatório. No presente artigo, incorporamos esta possibilidade de pensar os processos de patrimonialização em curso no Sertão Carioca como os de um sertão formal, ou seja, de pensar em muitos outros sertões transformados em parques.

Além disso, não só fazemos uso da obra de Magalhães Corrêa como registro dos modos de vida locais, como também procuramos resgatá-la enquanto matriz discursiva em torno da qual se atualizam os questionamentos feitos pelo autor em 1933 sobre a região e sua gente, através da perspectiva de seus próprios moradores, ou seja, os sertanejos. Em outras palavras, usamos O Sertão Carioca para pensar o Sertão Carioca transformado em parque.

Complementando nossa análise, cabe destacar que, além do Parque Estadual da Pedra Branca, a cidade do Rio de Janeiro abriga o Parque Nacional Floresta da Tijuca. Tomados um frente ao outro, eles podem, em termos ambientais e simbólicos, expressar o antagonismo entre os dois projetos distintos de nação aos quais nos referimos no dilema modernidade-sertão. A Floresta da Tijuca, modelada como um jardim imperial, remete à história oficial do país, enquanto o Parque Estadual da Pedra Branca conta a história do sertão e dos modos de vida rústicos de uma população entendida como autenticamente brasileira.

Na primeira seção, é feita uma reconstituição do imaginário conservacionista e das primeiras iniciativas de patrimonialização da natureza por meio dos parques, bem como de sua importância na construção de um imaginário ligado aos valores nacionais e de gestão do território. Em seguida, descrevemos a transformação do Sertão Carioca em parque e as novas orientações socioambientais que têm possibilitado os processos de patrimonialização em curso.

\section{PARQUES NACIONAIS: A NATUREZA COMO PATRIMÔNIO}

o descrever o processo de criação dos parques americanos, Barreto Filho (2001) de-
monstra que vários atributos e justificativas morais foram vinculados aos primeiros parques americanos posteriormente ao ato de sua criação. 0 próprio adjetivo nacional, tão naturalmente indissociado do conceito de parque, só foi elaborado 90 anos depois, na abertura da Primeira Conferência de Parques Mundiais em Seattle, em 1962. De acordo com Barreto Filho (2001: 68), nessa ocasião, os parques nacionais americanos foram apresentados pelo diretor do National Park Service como espaços nos quais a sensação provocada pelo contato com a natureza selvagem dos primeiros desbravadores da nação poderia ser experimentada por qualquer cidadão. 
Existe, portanto, uma gama de representações e imagens associadas aos parques nacionais que foram elaboradas e identificadas como práticas conservacionistas, desde as primeiras experiências dos parques americanos. Trata-se de um imaginário social elaborado sobre a conservação da natureza no qual os parques são evocados como sua maior expressão.

Reconhecendo a polissemia e a ambiguidade do conceito de imaginário social (Baczko, 1984; Legros et al, 2007) e de poder simbólico (Bourdieu, 2006), três significados são aqui utilizados: seu caráter de sistema simbólico da vida social, como instrumento estruturado e estruturante, ou seja, que comunica, faz conhecer e legitima determinadas práticas; o caráter utópico do desejo de uma outra sociedade em que a relação homem-natureza se apresenta de forma integrada; e o caráter de representação coletiva, de depositário da memória afetivo-social de uma cultura ou povo.

Assim, seu caráter público ganha também um sentido nacional, à medida que os parques passam a ser concebidos como guardiães de qualidades intrínsecas de uma nação: a beleza, a autenticidade de paisagens, a riqueza de sua flora e de sua fauna. São espaços reservados à conservação, mas que também evocam sentimentos de pertencimento, orgulho e identidade nacional e, por ambas as razões, devem permanecer intocados.

Gonçalves (1995) destaca, a este respeito, que os patrimônios operam justamente na integração simbólica das sociedades nacionais. Segundo o autor, a partir das revoluções burguesas dos séculos XVIII e XIX, os bens culturais, antes propriedades de grupos específicos e de acesso restrito, passam a ser percebidos como expressões artísticas de uma nação, de um povo. 0 acesso universal a bens culturais torna-se, portanto, uma condição fundamental para a formação de cidadão. Pode-se estender a mesma lógica aos bens naturais, por meio da experiência dos parques.

Tais ideais, produzidos nos Estados Unidos, foram transpostos para vários países, inclusive, a partir dos anos 1930, para o Brasil, onde a criação de parques nacionais também se inseriu em um contexto político de intensa reflexão sobre a identidade nacional e os caminhos possíveis de desenvolvimento (Franco; Drummond, 2005, Barreto Filho, 2001). No mesmo ambiente de debates dos anos 30, em que as preocupações com o mundo natural estavam conectadas com a questão da identidade nacional (Franco e Drummond, 2005), ganharam impulso as iniciativas oficiais de patrimonialização, com a criação em 1937 do Serviço do Patrimônio Histórico e Artístico Nacional (SPHAN). É possível, portanto, estabelecer uma correspondência entre as iniciativas de proteção de porções naturais únicas do território nacional ${ }^{4}$ e os bens culturais de nossa história oficial.

De Paula (2005: 245), referindo-se à relação do homem urbano com as áreas verdes, assim define a importância do caráter lúdico e civilizatório da interação com a natureza: 
A fuga da cidade é sobretudo a busca da tranquilidade e da afabilidade encontrada nas pequenas cidades do interior, seja nas montanhas, seja à beira de rios, represa, mar. Andar pelas matas, percorrer trilhas, banhar-se em cachoeiras, praticar cavalgadas, pescar, subir montanhas ou penhascos, todas essas são experiências que configuram o homo ludens; a maioria delas já arroladas como esportes (...) e esportes, como sabemos, são atividades que obedecem a regras, que são geridas por códigos que preconizam a civilidade.

O escotismo, o excursionismo ou montanhismo podem ser destacados como atividades lúdico-esportivas que desenvolveram regras específicas de convivência com a natureza e que são exaltadas por suas virtudes formadoras da cidadania. Essas atividades ganharam impulso com a progressiva criação de áreas protegidas, e suas práticas estão associadas ao que se entende por uso público em parques. Além dos aspectos civilizacionais já mencionados, o caminhar como uma prática estética (Careri, 2009) de apreensão e construção da paisagem tem a capacidade de produzir a perspectiva utópica de um mundo mais harmônico e integrado à natureza.

\section{AS PRIMEIRAS INICIATIVAS NO BRASIL}

$\mathrm{N}$ o ano de 1861, 5 foi feito o reflorestamento das serras do Maciço da Tijuca, na cidade do Rio de Janeiro, que transformou uma parcela deste na Floresta da Tijuca. A iniciativa decorreu de um decreto de D. Pedro II, considerado um marco na política de criação de parques no Brasil, pois, ainda que somente em 1961 a área tenha sido oficialmente definida como parque nacional, por ocasião do reflorestamento no século XIX já estavam presentes os valores que compõem o imaginário conservacionista: as orientações científicas de proteção dos recursos hídricos que abasteciam a cidade, os ideais românticos e civilizatórios associados à reserva do espaço para uso do público, em especial da elite carioca que desejava um refúgio de clima ameno para escapar da insalubridade urbana (Esterci e Fernandez, 2009; Fernandez, 2010).

As primeiras áreas protegidas, formalmente definidas como parques, foram criadas a partir da década de 1930, com o Parque de Itatiaia (1937), Serra dos Órgãos e Iguaçu (ambos em 1939). Também nesse período foram criados os primeiros códigos que legislavam sobre a temática ambiental.

\section{O JARDIM IMPERIAL E O SERTÃO CARIOCA}

cidade do Rio de Janeiro não só foi o berço do conservacionismo brasileiro, como
consiga em seu território dois parques cujas histórias estão relacionadas e permitem a
constro um instigante diálogo. Os detalhes desta história foram contados por Fernandez 
(2010), e neste artigo interessa destacar de que modo os dois parques explicitam o debate sobre a sertanidade nas políticas de conservação da natureza.

Localizados um em frente ao outro e denominados de acordo com o nome da montanha mais alta de seus respectivos maciços, os dois parques recriam em muitos planos os debates e representações elaboradas por intelectuais acerca da existência de um dualismo no processo de formação histórica do país: o Brasil cosmopolita das elites e o Brasil interiorano dos sertões.

Implantada no século XIX, a Floresta da Tijuca sofreu todo tipo de interferência na paisagem, sem que os ideais de conservação fossem contestados. Assim, foram construídas estradas, praças, belvederes, chafarizes, trilhas, pontes e lagos, além das interferências do paisagista francês Auguste Glaziou. A Floresta da Tijuca conseguiu desse modo realizar de forma plena os ideais de uso público, e simbolicamente integrar conservação e visitação do espaço protegido. Ao longo de sua existência, tem abrigado de forma bem-sucedida os múltiplos sentidos que envolvem a categoria parque. ${ }^{6}$

Já o Parque da Pedra Branca, instituído em 1974, teve também como uma das justificativas para sua criação a proteção dos mananciais que abastecem a zona oeste da cidade. Em estudo para a sua criação datado de 1971 (Fernandez, 2010), constava a existência de uma agricultura em decadência que não conseguia mais fazer frente ao processo de urbanização da região.

Como muitos outros parques no Brasil, definidos como parques de papel, ${ }^{7}$ no PEPB as formas prévias de ocupação não foram consideradas, como tampouco foram equacionadas suas condições fundiárias. Sem a dominialidade pública, há um conflito permanente entre os ideais de visitação pública e os espaços privados e ou comunitários de seus habitantes prévios. Os usos sociais do Sertão Carioca com sua gente "sertaneja" (Corrêa, 1933) subvertem assim os ideais civilizacionais e científicos atribuídos aos parques e, portanto, precisam ser invisibilizados. Em relação ao tema, Fernandez (2010: 153) descreve:

Para o excursionista que visita o PEPB, inspirado nos ideais dos parques americanos ou mesmo dos jardins, mirantes e estradas da Floresta da Tijuca, trata-se de uma experiência perturbadora. Intriga a este visitante a mistura entre o uso público e o uso privado das moradias, com seus portões, caminhos, plantações e animais. Também chama atenção o abandono institucional e a falta de infraestrutura para as atividades de lazer e turismo. Outros, contudo, se encantam com a rusticidade da região e combinam práticas de lazer tais como caminhadas e banhos de cachoeiras com o contato e interação com uma parcela de seus moradores.

Entre muitas possibilidades de "diálogo dos dois parques"8 em suas relações dinâmicas com a cidade, novas configurações se construíram pela temática do uso público. Está em 
curso, por exemplo, desde 2013, a implantação da Trilha Transcarioca. Concebido há mais de 20 anos por Pedro da Cunha Menezes, ${ }^{9}$ o percurso de longa duração (cerca de $180 \mathrm{~km}$ ) corta a cidade de Leste a Oeste, do bairro da Urca a Grumari, passando por seis UCs de proteção integral e uma de desenvolvimento sustentável (APA). Nos aspectos que é possível abordar neste artigo, a Trilha Transcarioca, além de interligar os dois parques e trazer a confrontação das experiências estéticas nas duas UCs, tem sofrido em sua concepção e modos de implantação uma crescente contestação ${ }^{10}$ por parte dos moradores do PEPB. Mais do que para a confrontação entre os usos públicos das trilhas e os usos comunitários dos caminhos construídos por seus moradores, queremos chamar atenção para a possibilidade de conjugação e ressignificação dos valores conservacionistas, na medida em que os moradores do PEPB assumem para si a tarefa de organizar o uso público ${ }^{11}$ em seus termos e, de modo distinto, mas também complementar, implantam atividades turísticas de base comunitária.

0 protagonismo dos moradores nas atividades de visitação do território tem incluído na representação da realidade (Bourdieu, 2006) paisagens híbridas formadas por espaços de conservação do ambiente natural e cultural e mostram, portanto, novos elementos a serem protegidos nesta área protegida.

\section{A PAISAGEM dO SERTÃo CARIOCA NO PARQUE ESTADUAL DA PEDRA BRANCA E AS NOVAS ORIENTAÇÕES SOCIOAMBIENTAIS}

s políticas institucionais de implantação do PEPB foram balizadas por parâmetros uni-
versais de implantação de parques. A adequação de suas instalações aos traços locais diz respeito apenas a elementos da flora e da fauna, mas não às formas históricas de ocupação da região. A única exceção se deu por iniciativa do antropólogo Darcy Ribeiro, que, na época da Conferência das Nações Unidas para o Meio Ambiente e o Desenvolvimento, também conhecida como Eco-92 ou Rio-92, estava à frente da Secretaria Extraordinária de Programas Especiais do Rio de Janeiro (SEEPE) do Governo Leonel Brizola. O projeto de implantação do PEPB $^{12}$ foi elaborado como preparativo para a Rio-92 e tinha como objetivo divulgar a existência do parque, então desconhecido, para os cariocas e visitantes da Conferência. Buscava-se, com a iniciativa, estabelecer uma clara associação com a Floresta da Tijuca, acionando os elos históricos entre os dois parques (Fernandez, 2010).

0 resgate dos elementos históricos da região permaneceu também na proposta de Darcy Ribeiro de incentivar o transporte de turistas e funcionários do Parque em mulas (que chegaram a ser compradas), meio de locomoção tradicionalmente utilizado pelos sitiantes da região. Mas nenhuma de suas sugestões relativas à incorporação de imagens do Sertão 
Carioca foi adotada, visto que essa perspectiva contrariava as orientações conservacionistas, caracterizadas pelo tratamento de ocultamento dado aos conflitos e usos locais.

Contudo, de modo espontâneo, algumas marcas do Sertão Carioca foram incorporadas pelos visitantes e tornaram-se marcos oficiais do Parque. Assim, a trilha da Casa Amarela referia-se à construção de 1929, moradia de uma família de agricultores. Hoje desabitada, a casa é um marco para se chegar no cume da Pedra Branca e faz a ligação da localidade do Pau da Fome com Vargem Grande.

A orientação institucional de incorporar ao uso público do Parque a interpretação ambiental (voltada para a fauna, a flora, a formação geológica etc.), aos poucos e a contragosto, absorveu a história social do território que igualmente deixou suas marcas na paisagem. As formas mais fáceis de assimilação pela administração do Parque são aquelas que remetem aos usos extintos do Sertão, tais como ruínas de casas, de carvoarias, objetos arqueológicos, marcos topográficos com nomes de famílias antigas, ou usos históricos. Contudo, para desalento de dirigentes ambientais de perfil conservacionista, o Sertão Carioca permanece de modo dinâmico nas práticas cotidianas dos agricultores.

O problema maior é o cara que está amarrado com a terra, mas um dado positivo é que os agricultores antigos estão morrendo. Penso mesmo que a tendência é o abandono da agricultura. Agora tem aqueles que têm prazer na atividade. A grande sorte nossa, é que o jovem não tem mais interesse em agricultura (Ex-gestora do PEPB, 2006, apud Fernandez, 2009: 274).

Assim, este movimento se deu menos pelas intenções dos agentes institucionais que administravam o Parque do que pela ação estratégica de mediadores e pesquisadores que, como afirma Bourdieu (2006), exercem seu poder de colocar na realidade a representação da realidade e desse modo contribuem com os anseios dos moradores para afirmar seus modos de vida e permanecer no território.

Essas novas perspectivas, que exerceram seus efeitos locais, expressavam uma mudança mais ampla do processo de redemocratização da sociedade brasileira, que se refletiu na elaboração do texto da Constituição e de legislações infraconstitucionais. Passaram a constar nesses códigos a exigência da participação social e da consideração de formas culturalmente diversas de organização de diferentes grupos que compõem a sociedade brasileira. E, sobretudo, colocou-se o tema da conservação da biodiversidade em condições de igualdade com a diversidade cultural. Mais do que isso, a leitura transversal da Constituição permite compreender a relação intrínseca entre esses dois aspectos.

Um processo semelhante ocorreu nas políticas de patrimonialização. As orientações elitistas que instruíram as primeiras iniciativas do SPHAN, entre as décadas de 1930 e 1960, 
foram confrontadas por novas perspectivas sobre o que se entende como cultura brasileira. A partir do início da década de 70, esta seria retratada pela diversidade de culturas e modos de vida dos grupos populares nas diferente regiões e localidades brasileiras (Gonçalves, 1995).

Voltando aos debates da Constituinte, Santilli (2005) apresenta as discussões que resultaram na redação do texto constitucional e produziram uma concepção integrada do patrimônio natural e cultural. Ganhou força o entendimento de que a reprodução física e cultural de populações indígenas, quilombolas e outros grupos tradicionais só seria possível se fossem assegurados os recursos naturais de seus territórios. Segundo a autora (2005: 70), as referências constitucionais ao meio ambiente não constam apenas no artigo 225, mas podem ser encontradas de modo transversal em diversos outros capítulos que versam sobre economia, reforma agrária, saúde, educação, ciência e tecnologia e nas políticas setoriais.

0 viés participativo com ênfase na diversidade cultural e diferentes modos de vida locais registrados no texto constitucional de 1988 são expressão de movimentos sociais diversos, dos chamados excluídos do modelo desenvolvimentista e também aqueles ameaçados de remoção por políticas de criação de áreas protegidas restritivas, que passaram a reivindicar territórios e formas culturalmente específicas de produção de seus meios de vida.

0 caso mais emblemático nesse cenário foi a luta dos seringueiros liderados por Chico Mendes na Amazônia, que reivindicavam uma reforma agrária compatível com suas práticas extrativistas. Suas reivindicações foram vistas como compatíveis com os ideais ambientalistas de cuidado com a natureza e equilíbrio com o ecossistema amazônico. A luta dos seringueiros ambientalizou-se, e a repercussão internacional do movimento resultou na criação em 1990 da primeira área no Brasil de desenvolvimento sustentável, a Reserva Extrativista do Alto Juruá, para insatisfação dos conservacionistas que viam as políticas sociais e as políticas de conservação do ambiente como assuntos que não deveriam ser misturados. A partir desse momento, o conservacionismo brasileiro passou a ser confrontado pelas novas orientações socioambientais que afirmavam a compatibilidade entre a conservação da natureza in situ e a promoção do desenvolvimento das populações locais.

Para além das conquistas no texto constitucional, a elaboração do SNUC representou, no plano das políticas ambientais de conservação da natureza, as novas orientações de equidade entre biodiversidade e sociodiversidade. Foram oito anos de debates entre 1992 e 2000, e nesse contexto foram formalizados dois tipos de unidades de conservação: as de uso indireto ou de proteção integral e as de uso direto ou de desenvolvimento sustentável. Também no corpo dessa lei apareceu a figura populações tradicionais. ${ }^{13}$ Nesse momento, contudo, a definição de populações tradicionais foi vetada como solução para permitir que cada grupo interessado em reivindicar a tradicionalidade fosse avaliado de acordo com suas condições específicas. 
Em 2007 foi elaborada a Política Nacional de Desenvolvimento Sustentável dos Povos e Comunidades Tradicionais, ${ }_{1}^{14}$ e finalmente definiu-se que Povos e Comunidades Tradicionais são:

Grupos culturalmente diferenciados e que se reconhecem como tais, que possuem formas próprias de organização social, que ocupam e usam territórios e recursos naturais como condição para sua reprodução cultural, social, religiosa, ancestral e econômica, utilizando conhecimentos, inovações e práticas gerados e transmitidos pela tradição.

Ainda que tenham avançado os processos de formalização dos direitos de populações tradicionais, Santilli (2005: 85) destaca que as populações indígenas e quilombolas gozam de um regime jurídico privilegiado com relação às demais populações tradicionais que não têm direitos expressamente assegurados na Constituição. Mesmo o SNUC, que garantiu alguns princípios socioambientais, é tido como uma lei híbrida, porque de um lado formaliza as reservas de uso sustentável e garante princípios participativos para a criação e gestão de UCs, e de outro fala na permanência de populações tradicionais em UCs de proteção integral, apenas de modo temporário e mediante a elaboração de termos de compromisso. ${ }^{15}$

Voltando ao Parque Estadual da Pedra Branca, observa-se que a vigência do SNUC a partir da década de 2000 foi acionada pelos órgãos ambientais estaduais inicialmente para explicitar a ausência de direitos das populações residentes nos parques (Fernandez, 2009). Mesmo assim, seguindo a exigência legal explicitada nesse código para a criação de conselhos consultivos, grupos organizados de moradores, agricultores e instituições buscaram ocupar esse espaço de participação para garantir o acesso à informação sobre temas do seu interesse e o reconhecimento de seus direitos de permanência. A primeira formação participativa do Conselho foi oficializada em 2009.

No período de dezembro de 2011 a julho de 2013, os conselheiros participaram da elaboração do plano de manejo do Parque e buscaram questionar alguns princípios do roteiro metodológico desse instrumento que desfavoreciam soluções de compatibilização entre os usos históricos e a conservação da natureza. ${ }^{16}$ Outro desdobramento dessa mobilização foi a decisão de alguns conselheiros de realizar reuniões em diversas localidades do Maciço da Pedra Branca para informar moradores não organizados sobre os riscos de planos de regularização fundiária que poderiam ser realizados como desdobramentos do plano de manejo.

Articulação e Mobilização em Defesa da Moradia convida para domingo dia 03 de março de 2013, às 10hs da manhã, reunião com diversos segmentos e movimentos em defesa da moradia para preparar e conscientizar os moradores de seus direitos, tendo como principal objetivo ajudar a organizar juridicamente esta comunidade. Este será nosso terceiro encontro. Começamos pelo Alto Camorim. No domingo passado estivemos na comunidade Monte da Paz - no Pau da 
Fome - e seguiremos nossa caminhada em defesa de vidas. Moradia, direito básico de todo ser. As comunidades próximas ou dentro do Parque Estadual da Pedra Branca estão ameaçadas com a desculpa de preservar o meio ambiente, esqueceram que quando o parque foi criado em 1974 nós já estávamos aqui e se existe preservação é porque durante décadas nós lutamos e protegemos. Companheiros, precisamos nos organizar e lutar pela nossa permanência onde construímos nossas vidas e não permitir que destruam nossa história e nossos sonhos. Contamos com a presença de todos. Atenciosamente, organização em defesa da moradia. (Representante da Comunidade Alto Camorim no Conselho do PEPB em 03 mar, 2013).

A reunião supracitada acabou sendo realizada no dia 17 de março de 2013, na localidade do Alto Mucuíba, em Vargem Grande, e nesse contexto surgiram falas de moradores antigos evocando seus vínculos de pertencimento com o território, relações de parentesco e descendência de escravos. Nasceu nesse momento uma mobilização em torno da tradicionalidade e a posterior solicitação de reconhecimento da identidade quilombola à Fundação Palmares. 0 mesmo pedido já havia sido feito a essa instituição pela comunidade do Alto Camorim (localidade próxima) no ano de 2004. A titularidade das duas comunidades foi emitida no dia 16 de agosto de 2014.

0 reconhecimento formal da identidade quilombola mudou o status dessas comunidades em suas relações com o órgão ambiental responsável pela administração do Parque, já que os quilombolas têm direitos territoriais assegurados pela Constituição. Nesse caso, são os princípios da conservação que devem ser compatibilizados com os usos tradicionais quilombolas, e não o contrário (Santilli, 2005).

Para além das ações no Conselho, a ação de mediadores de ONGs e instituições identificadas com valores da agroecologia promoveu um gradual processo de mobilização e ressignificação das práticas agrícolas no Maciço da Pedra Branca. Pode-se sinalizar a década de 2000 como marco desse processo, com a criação de associações de agricultores e a conversão orgânica de alguns de seus membros.

A partir de 2010, a inserção dos agricultores da Pedra Branca em feiras orgânicas do Circuito Carioca ${ }^{17}$ na zona sul, e posteriormente na zona oeste, permitiu aos agricultores divulgar seus espaços de vida em outros cantos da cidade (Prado; Matos; Fernandez, 2012).

Sem dúvida, as práticas agrícolas são componentes da identidade quilombola, mas esta não abarca a totalidade dos agricultores residentes no Maciço. Junto ao empenho pelo reconhecimento de grupos específicos na Pedra Branca como tradicionais, nos fóruns locais de participaçãa ${ }^{18}$ há um esforço para que a atividade agrícola seja reconhecida como uma atividade tradicional, porque realizada em determinadas condições técnicas, culturais e ambientais. 


\section{PAISAGENS E PATRIMÔNIO: O QUE MERECE SER PROTEGIDO NO PARQUE ESTADUAL DA PEDRA BRANCA}

s novas orientações socioambientais a que nos referimos anteriormente têm incorpo-
rado a dimensão da agrobiodiversidade (Santilli, 2009), destacando o papel milenar da agricultura e da domesticação de plantas para a diversidade genética e a produção de alimentos. Neste sentido, o sistema agrícola com todos os seus elementos - plantas e animais, objetos, técnicas, conhecimentos, alimentos e espaço - conforma uma paisagem merecedora de conservação e patrimonialização, seja pelos seus condicionantes ambientais, seja pela sua engenhosidade e autenticidade cultural. ${ }^{19}$

Podemos encontrar na obra O Sertão Carioca (1933) um precioso registro histórico desse campesinato e de suas atividades: o cultivo da banana, a pesca e as atividades artesanais, como o trabalho das esteireiras que faziam uso da taboa, do junco e da tiririca recolhidos nos campos e lagoas; dos cesteiros que utilizavam cipó e bambu em seus balaios, peneiras e jacás; dos tamanqueiros que buscavam madeira leve para fazer formas de sapateiro, tamancos, colheres de pau, gamelas etc.; dos cabeiros que retiravam das matas troncos adequados para fabricar cabos para ferramentas; dos oleiros que produziam telhas, tijolos e vasos de cerâmica. E ainda a especialização na construção de casas de pau-a-pique.

A obra pode assim ser utilizada como um registro etnográfico do sistema agrícola local, uma vez que permite a compreensão integrada desses elementos, ao apresentar "os sertanejos", com suas técnicas, objetos, casas, lavouras, ritos, saberes e inúmeras outras atividades, fruto de uma relação indissociável entre o homem e o ambiente. Neste sentido, a paisagem percebida como um documento que expressa as marcas dos diferentes usos humanos na floresta é também uma paisagem incorporada pela experiência de vida e pelas dinâmicas do trabalho. De acordo com Esterci (1987: 100), "o ser morador implica também um período de maturação que tem a ver não apenas com o ciclo de desenvolvimento das plantas e edificações, mas com as próprias relações construídas no lugar". Assim, a disposição dos sítios no Maciço da Pedra Branca conta a história de vida das pessoas e de seu habitar nesse espaço ao longo do tempo.

Como marcos institucionais desse debate (Santilli, 2010), destacam-se a Conferência das Nações Unidas sobre Meio Ambiente e Desenvolvimento, no Rio de Janeiro, no ano de 1992, que enfatizou as interrelações entre o natural e o cultural a partir da adoção da categoria paisagem cultural. Em 2000, A Convenção Europeia da Paisagem estabeleceu normas de proteção e gestão de todas as formas de paisagens e incentivou a participação dos cidadãos nas decisões sobre as políticas relativas às paisagens nas quais vivem. Em 2009, o Brasil criou 
um instrumento nacional de reconhecimento das paisagens culturais brasileiras denominado chancela e regulado pela Portaria no 127, de 30/04/2009, do IPHAN (apud Santilli, 2010). Tal instrumento foi criado com fundamento no artigo 216, parágrafo 10 da Constituição, que determina que o poder público, com a colaboração da comunidade, promoverá e protegerá o patrimônio cultural brasileiro por meio de inventários, registros, vigilância, tombamento, desapropriação e "outras formas de acautelamento e preservação". Até o momento, no entanto, trata-se de um instrumento jurídico com pouca clareza quanto à sua aplicação efetiva (Vasconcelos, 2012).

Também deve-se destacar que em termos teóricos o adjetivo cultural é questionado, visto que se entende contemporaneamente que toda paisagem é necessariamente cultural ou inventada (Cauquelin, 2007), já que é fruto de inúmeras mediações sociais. De todo modo, a projeção recente conferida à categoria paisagem cumpre o papel de pôr em evidência uma compreensão ampliada das formas de integração sociedade e natureza e o reconhecimento de modos de vida diversos, que, em interação com o ambiente, necessitam da manutenção de seu território para continuar a existir.

Nessa conjuntura, novos e emblemáticos sentidos têm sido atribuídos às culturas agrícolas da Pedra Branca, em especial o caqui e a banana. Pelo quinto ano consecutivo a Rede Carioca de Agricultura Urbana organizou o Dia do Tira-Caqui, sempre em 21 de abril, como um dia em que consumidores visitam uma propriedade, e podem vivenciar o modo de vida do agricultor e as dificuldades que envolvem seu trabalho.

A projeção dos agricultores nos mercados orgânicos/agroecológicos, a aproximação com chefes de cozinha e movimentos de relocalização de alimentos e segurança alimentar resultaram na premiação, em dezembro de 2015, da banana de Vargem Grande como Maravilha Gastronômica do estado do Rio de Janeiro, na categoria "terra". O prêmio teve o patrocínio do Senac-Rio ${ }^{20}$ e do Governo do Estado. Paradoxalmente, esse mesmo Governo, em sua instância ambiental, ainda criminaliza o cultivo de bananas no PEPB. ${ }^{21}$ Tratou-se, por isso, de um evento de grande simbolismo: os agricultores de Vargem Grande serem recebidos e agraciados com a premiação no Palácio Guanabara, sede do Governo de estado.

0 caso da banana, simultaneamente criminalizada e premiada, põe em evidência o embate entre concepções distintas sobre o que merece ser protegido nessa área protegida. De acordo com Fernandez, Oliveira e Dias (2015), uma agenda interdisciplinar de pesquisa incluindo Ciências Sociais, Geografia, História e Ecologia pode trazer novas perspectivas sobre a proteção de paisagens. Destacam-se: a) os estudos sobre processos de interação, adaptação e coevolução entre homem e natureza, b) a historicidade dos critérios objetivos das legislações e estudos ecológicos que classificam plantas e homens como exóticos, invasores ou nativos em 
unidades de conservação, e, por fim, c) valores, práticas e conhecimentos locais que "tornam nativos" plantas, homens e animais.

Outro desdobramento da crescente notoriedade dos agricultores da Pedra Branca nos mercados alternativos foi a reportagem de capa de domingo do jornal O Globo, com o título O Sertão Carioca (Briso e Marenco, 2015). Para sua produção, os dois jornalistas passaram uma semana na localidade do Rio da Prata, acompanhando a atividade cotidiana de alguns agricultores. Trata-se de uma reportagem sensível aos modos de vida locais, que, no entanto, enfatiza certo exotismo e isolamento dos moradores do "Sertão Carioca", aspectos que corresponderam, em grande medida, às expectativas dos próprios agricultores que guiaram a visita dos jornalistas. Se, como vimos anteriormente, o discurso da perda (Gonçalves, 1995) justifica as medidas de salvaguarda da natureza por meio da criação dos parques, na fala do agricultor também se observa a melancolia de ser um remanescente de um modo de vida em vias de desaparecimento.

Quando eu era criança, tinha muita gente nesta serra, a gente tinha a maior alegria dia de domingo, de jogar bola, pelada, nos terreiros, ia no terreiro de um do outro, hoje você não vê mais isso, não vê mais nada. Tem pouca gente. Tem as pessoas que a gente conhece prá dentro do mato, mas hoje a maioria das pessoas tem suas casas lá embaixo. Quem já tá aqui tá, mas devagar vai morrendo, vai saindo fora e vai virando floresta que nem tá isso aí. Isso aí eu tenho tristeza mesmo. Acho que no futuro, isso vai ficar na história (Claudino da Costa apud Briso e Marenco, 2015).

Inúmeras leituras têm sido feitas pelos mediadores de organizações e instituições que atuam com foco no sistema agroalimentar local. Mas esta reportagem e a produção de outros discursos indicam que os agricultores são também portadores de suas próprias interpretações sobre a paisagem e suas histórias. Em outros momentos da mesma reportagem, o agricultor sinaliza para a reinvenção dessa agricultura por meio dos mercados alternativos:

O pessoal lá de Ipanema, de Copacabana, no Leblon, na Tijuca, já compra nossos produtos. A gente foi criado aqui no mato, quando falava de Copacabana, eu escutava era no rádio!

(...) A gente era orgânico e nem sabia. Nunca tinha ouvido essa palavra. (...) Há cinco anos, quando as feiras orgânicas começaram, tinha gente aqui em cima que me chamava de maluco. Atravessar a cidade para fazer feira, onde já se viu? Em Ipanema, a gente dava bom dia e as pessoas não respondiam. A gente era bronco mesmo, até deprimia. (Claudino da Costa apud Briso e Marenco, 2015).

A fala deste "sertanejo" da atualidade nos permite estabelecer conexões com algumas das questões problematizadas por Corrêa em sua obra O Sertão Carioca: a ameaça de 
desaparecimento dessa agricultura rústica frente ao processo de urbanização, a imposição crescente de novas racionalidades capitalistas, o contraste cultural do "roceiro" frente aos hábitos citadinos. $E$, assim como o agricultor Claudino fala dos novos vínculos do Sertão com a cidade, Corrêa também idealiza novas formas de convivência e respeito entre o sertão e a cidade.

0 que mais me impressionou em Paris, em pleno Boulevard Raspail, foi um homenzinho com uma trompa, som rouco, anunciando queijo de cabra, em companhia de umas trinta belíssimas cabras. Como é diferente a mentalidade dos povos civilizados. (...)

Como verdadeiros abnegados, lutando contra todos os elementos e, finalmente abandonados por nossos dirigentes; quando por ventura, cometem qualquer delito, aplica-se-lhes logo a lei, mas a lei feita para 'almofadinha da cidade', não há compreensão de seu meio, de sua mentalidade e de sua vida rural (Corrêa, 1933: 142).

Analisando o conjunto de transformações que incidem no Maciço da Pedra Branca, observa-se que estas são resultado das novas conjunturas jurídico-institucionais e das formas de mobilização local que ressignificam as relações de seus moradores com os órgãos ambientais e trazem reconhecimento político e econômico em outras instâncias da vida social e frente à cidade. Entre o passado idealizado e a ameaça de desaparecimento dos modos de vida do Sertão Carioca, o futuro acena com a reinvenção de tradições, sob novos olhares socioambientais.

\section{Notas}

1 Ao longo do texto, a abreviatura UC será utilizada para designar unidade de conservação.

2 Este artigo faz uso de fontes bibliográficas, documentos, artigos de imprensa, além de atividades de observação participante em reuniões do Conselho Consultivo do Parque Estadual da Pedra Branca, da Rede Carioca de Agricultura Urbana, associações agrícolas, feiras e festas locais.

3 A publicação reúne crônicas publicadas pelo autor entre 1932 e 1933 no jornal Correio da Manhã.

4 Posteriormente, a criação de áreas protegidas também pôde ser compatibilizada com os ideais dos governos militares de assegurar reservas estratégicas de recursos naturais como condição de soberania do país (Esterci e Fernandez, 2009).

5 Embora nesta data tenha sido criada oficialmente a Floresta da Tijuca e das Paineiras, uma série de estudos, medidas de desapropriação e ações de replantio vinham sendo tomadas desde 1844 (Drummond, 1988: 287).

6 Deve-se destacar que o título de parque conferido à floresta em 1961 não recebeu adesão da população carioca, talvez pelo poder simbólico atribuído a seu nome histórico. Também pode-se argumentar que a floresta é a principal representação imagética dos parques, cumprindo assim a mesma atribuição de valores. 
7 Expressão usada para designar parques criados legalmente, mas não implantados de fato.

8 Como se esses espaços protegidos fossem dotados de vida própria.

9 Montanhista, conservacionista, ex-diretor do Parque da Tijuca. É colunista da revista eletrônica de perfil conservacionista $O E c o$.

10 Os moradores têm participado ativamente das reuniões da Câmara Temática de Uso Público do Conselho do PEPB, e suas críticas contundentes à implantação da Trilha Transcarioca em rede social (10 dez. 2015) provocaram uma reunião com os organizadores da Trilha, moradores e gestores do Parque em 16 de janeiro 2016.

11 A visitação e a fruição da natureza tal como são concebidas institucionalmente nos parques.

120 projeto foi realizado pela SEEPE e pela Secretaria de Estado de Meio Ambiente e Projetos Especiais (SEMAM), e executado pelo Instituto Estadual de Florestas (IEF).

13 Barreto Filho (2006) destaca que o termo populações tradicionais foi "inventado" na década de 1970 no âmbito do conservacionismo internacional, a partir dos debates sobre zoneamentos de parques e da tentativa de equacionar a conservação da biodiversidade com o desenvolvimento socioeconômico local. As zonas antropológicas seriam assim áreas destinadas às populações com características culturais específicas e entendidas como parte do ecossistema. No Brasil, no entanto, por força do forte imaginário conservacionista e sua influência nas agências governamentais, o tema da permanência das populações humanas só apareceu de forma clara na agenda de discussão dos órgãos gestores em 1992, no projeto de lei para elaboração do SNUC.

14 PNPCT, Decreto n. 6.040/ 7 fev. 2007, artigo 3ㅜ, inciso I.

15 Conforme o Decreto 4.340, de 22 de agosto de 2002, que regulamenta artigos da Lei 9.985, SNUC (Brasil, 2002).

16 As principais considerações dos conselheiros foram registradas no documento Posicionamento do ConseIho Consultivo sobre o plano de manejo do PEPB, em 6 de junho de 2012. Disponível em: <http://sertaocarioca.org.br/2012/06/posicionamento-do-conselho-consultivo-do-parque-estadual-da-pedra-branca-sobre-a-elaboracao-do-plano-de-manejo/>. Acesso em: 12 jan. 2016.

170 Circuito Carioca de Feiras Orgânicas foi inaugurado em 2010 pela Secretaria de Desenvolvimento Social e Solidário (SEDES) e a Secretaria de Ordem Pública (SEOPS) da Prefeitura do Rio de Janeiro.

18 Conselho Consultivo do PEPB e Rede Carioca de Agricultura Urbana.

19 Em 2010, o Instituto do Patrimônio Histórico Artístico e Nacional (IPHAN) reconheceu o Sistema Agrícola Tradicional do Rio Negro (Amazonas) como patrimônio cultural brasileiro (ISA, 17 jun. 2015).

20 Serviço Nacional de Aprendizagem Comercial.

21 É frequente a ameaça de retirada dos bananais - e consequentemente de remoção de seus produtores sob a acusação de que se trata de uma planta exótica e cuja presença é incompatível com uma UC. Estudos interdisciplinares, no entanto, descartam o potencial invasivo da banana e destacam sua existência centenária no território (Fernandez; Oliveira; Dias, 2015). 


\section{REFERÊNCIAS BIBLIOGRÁFICAS}

BACZKO, B. Imaginação social. In: Enciclopédia Einaudi. Lisboa: Imprensa Nacional/Casa da Moeda, 1984.

BARRETO FILHO, H. T. Da nação ao planeta através da natureza: uma abordagem antropológica das unidades de conservação de proteção integral da Amazônia brasileira. Tese (Doutorado em Antropologia) - Faculdade de Filosofia Letras e Ciências Humanas, Universidade de São Paulo. São Paulo, 2001.

Notas para uma história social das áreas de proteção integral no Brasil. In: Terras indígenas \& Unidades de Conservação da Natureza: o desafio das sobreposições. São Paulo: Instituto Socioambiental, 2004.

Populações tradicionais: introdução à crítica da ecologia política de uma noção. In: ADAMS, C.; MURRIETA, R.; NEVES, W. (orgs.). Sociedades caboclas amazônicas: modernidade e invisibilidade. São Paulo: FAPESP, 2006. p.109-143.

BOURDIEU, P. O poder simbólico. 9a ed. Rio de Janeiro: Bertrand Brasil, 2006.

BRISO, C. B.; MARENCO, D. 0 sertão carioca. O Globo, Rio de Janeiro, 4 out. 2015. Disponível em: < http:// oglobo.globo.com/rio/o-sertao-carioca-17660130> Acesso em: 5 jan. 2016.

CARERI, F. Walkscapes: el andar como practicaestetica. Barcelona: GG, 2009.

CAUQUELIN, A. A invenção da paisagem. São Paulo: Martins Fontes, 2007.

CORRÊA, A. M. O sertão carioca. Rio de Janeiro: Imprensa Nacional, 1933.

DE PAULA, S. G. Natureza, ruralidade e experiência urbana. In: MOREIRA, José Roberto (org.). Identidades sociais: ruralidades no Brasil contemporâneo. Rio de Janeiro: DP\&A, 2005.

DRUMMOND, J. A. 0 jardim dentro da máquina: breve história ambiental da Floresta da Tijuca, Estudos Históricos, Rio de Janeiro, v. 1, n. 2, p. 276-298, 1988.

ESTERCI, N. Conflito no Araguaia: peões e posseiros contra a grande empresa. Petrópolis: Vozes, 1987.

; FERNANDEZ, A. O legado conservacionista em questão, Revista Pós-Ciências Sociais, v.6, n. 12, p.1540, 2009.

FeRnANDEZ, A. Do Sertão Carioca ao Parque Estadual da Pedra Branca: a construção social de uma unidade de conservação à luz das políticas ambientais fluminenses e da evolução urbana do Rio de Janeiro. Tese (Doutorado em Sociologia) - Programa de Pós-Graduação em Sociologia e Antropologia. Universidade Federal do Rio de Janeiro. Rio de Janeiro, 2009.

Um Rio de florestas: uma reflexão sobre o sentido de criação dos parques na cidade do Rio de Janeiro, Estudos Históricos, v. 24, n.47, p.141-161, 2010.

; OLIVEIRA, R. R.; DIAS, M. C. O. Plantas exóticas, populações nativas: humanos e não humanos na paisagem de uma UC de Proteção Integral, Tessituras, Pelotas, v. 3, n. 1, p. 121-153, jan./jun. 2015.

FRANCO, J. L; DRUMMOND, J. A. Armando Magalhães Corrêa: gente e natureza de um sertão quase metropolitano. Hist. cienc. Saúde, Manguinhos, v.12, n.3, Rio de Janeiro, set./dez. 2005.

GONÇALVES, J. R. S. Em busca da autenticidade: ideologias culturais e concepções de nação no Brasil. In: VILLAS BÔAS, G.; GONÇALVES, M. A. O Brasil na virada do século: o debate dos cientistas sociais. Rio de Janeiro: Relume Dumará, 1995. 
IMAGENS mostram plantações ilegais de banana em parque ambiental no Rio. G1, 27 de maio de 2011. Disponível em: http://g1.globo.com/rio-dejaneiro/noticia/2011/05/imagens-mostram-plantacao-ilegal-de-bananas-em-parqueambiental-no-rio.html. Acesso em: 25 jan. 2011.

LEGROS, P. et al. Sociologia do imaginário. Porto Alegre: Sulina, 2007.

PRADO, B. de A.; MATTOS, C; FERNANDEZ, A. C. F. Agricultores do Maciço da Pedra Branca: em busca de reconhecimento de seus espaços de vida, Revista Agriculturas, v. 9, n. 2, p. 6-9, set. 2012.

PROJETO MARAVILHAS GASTRONÔMICAS. Disponível em: <http://projetomaravilhas.com.br/>. Acesso em: 14 jan. 2016.

SANTILLI, J. Sociambientalismo e novos direitos: proteção jurídica à diversidade biológica e cultural. São Paulo: Peirópolis, 2005.

. Agrobiodiversidade e direitos dos agricultores. São Paulo: Peiropólis, 2009.

Paisagens culturais. Instituto Socioambiental. Disponível em: <http://uc.socioambiental.org/\%C3\% A1 reas-de-patrimonio-cultural/paisagens-culturais>. Acesso em: 5 jan. 2016.

SARMENTO, C. E. Pelas veredas da capital: Magalhães Corrêa e a invenção formal do sertão carioca. Rio de Janeiro: CPDOC, 1998. Disponível em: <www.cpdoc.fgv.br>. Acesso em: 4 abr. 2009.

TRILHA TRANSCARIOCA. Disponível em: <https://www.facebook.com/TrilhaTranscarioca/?fref=ts>. Acesso em: 22 jan. 2016.

VASCONCELOS, M. C. de A. As fragilidades e potencialidades da chancela da paisagem cultural brasileira, Revista CPC, São Paulo, n.13, p. 51-73, nov. 2011/abr. 2012. 